\title{
Uma longa viagem
}

Octavio lanni

Todo aquele que migra sabe de onde parte mas não sabe onde chega; sabe o caminho que deixa mas não sabe qual encontra. Lança-se em uma travessia sem fim, acreditando-se sempre o mesmo, mas poucas vezes dando-se conta de que se preserva e se transforma, reafirma e transfigura, afina e desafina. Lá longe, em outro lugar, país ou continente, continua a rememorar a partida e o caminho percorrido, recriando situações, pessoas, vivências, imagens, diálogos, sentimentos, memórias, fragmentos, esquecimentos. É assim, com recordações e esquecimentos, que o migrante nutre a nova situação, seja ela de êxito, seja de frustração.

Está impregnado de um passado que nunca se apaga, mesmo quando é esquecimento. R essoa sempre contínua e episodicamente, nas coisas, gentes, situações, sentimentos, imaginários, sonhos e alucinações. É um passado que povoa o presente, sejaqual for a geração. $\mathrm{N}$ o contraponto de presente e passado, passado e presente, aos poucos se dá a metamorfose das adversidades em façanhas, da biografia em gesta, da história em mito.

E o presente se impõe sempre como uma realidade viva, inquestioná vel. Pode ser prosaico, estranho, assustador ou fascinante. Aí acontece 0 êxito e a realização, tanto quanto o desespero e a alucinação.

R occo e seus irmãos é um filme sobre a migração de uma família, de Lucania para M ilão. Aí estão em questão o sul e o norte, 0 terrone e 0 polentone, o campo e a cidade, a comunidade e a sociedade. Ao mesmo 
1. Ver Visconti (1967). Além do "R oteiro de filmagem", o livro reúne estudos de vários autores italianos sobre esse filme e a filmografia deV isconti. tempo, aí estão em questão a urbanização e a individuação, o trabalho e a profissão, o êxito e a frustração, a diligência e a delinqüência. Fogem do passado para o presente.

A cidade é o palco em que se movem todos, determinados e atônitos. $\mathrm{N}$ ela buscam localizar- se, estabelecer pontos de referência, criar as condições mínimas de sobrevivência, descortinar dias melhores. Q uerem trabalho e bem-estar. Estão fugindo de séculos de servidão ${ }^{1}$.

Vincenzo fora o primeiro, chegara antes, estava empregado, fizera amigos, namorava. Sabia da família lá longe; que o pai havia morrido; que a mãe lutava com os outros filhos para sobreviver na adversidade reverberando difíceis condições de trabalho na terra. Surpreende- se com a chegada da família, como se fosse algo não só inesperado mas fora de hora, indesejado. Era como um terremoto, abalando a situação em que se achava. Em vez de continuar o migrante solitário que se situava aos poucos, teve de assumir-se como filho e irmão.

M as, mãe... Por que a senhora não me escreveu dizendo que vinha com todo 0 mundo? Q uando aconteceu a morte de meu pai a senhora me escreveu... E eu respondi que primeiro era preciso ver se havia trabalho.. pra eles... e depois... (Visconti, 1967).

R osaria é a mãe sempre vestida de preto, guardando luto por toda vida, em memória do marido, Antonio, falecido lá longe, no paése. D ecidiu migrar para a cidade para que os filhos pudessem se empregar, se profissionalizar, desfrutar de alguma segurança econômica, realizar-se. Trouxe os quatro que com ela estavam, para que seguissem o caminho de V incenzo, que já havia percorrido anteriormente a estrada, em busca da cidade. Em pouco tempo, no entanto, ela se dá conta de que a cidade é labiríntica e turbulenta.

É minha a culpa por tudo isso que está acontecendo? É minha a culpa se tive a ambição de trazer meus filhos, belos e fortes, pra cidade, pra que ficassem ricose ganhassem importância sem se envilecerem presos à terra como o pai, esmagado cem vezes antes de fechar os olhos pra sempre? [...] Teu pai nunca quis deixar aquela terra. M as eu sim. Q uis por causa de Vincenzo, e de Simone, e de R occo. E nem sei o que é que desejava pra eles. 0 mundo inteiro teria me parecido pouco. A certa altura pensei ter conseguido aquilo que sonhava... M eu R occo foi-se embora, e seus olhos parecem os olhos de quem viu o inferno. Simone caiu nas 
mãos de uma mulher da vida. M aldito o dia em que saí da terra de teu pai! Jesus C risto ainda há de ter remorso por tudo aquilo que nos faz sofrer! (Idem, pp. 251 e 286).

Simone é vivo, esperto, ágil, instintivo, com senso de oportunidade e facilidade. Logo se insere na academia de boxe, como pugilista. Aí alcança êxito, desfruta da boemia e do dinheiro fácil, protegido pelo diretor da academia que admira o seu porte apolíneo. C onhece e apaixona-se por $\mathrm{N}$ adia, mulher independente, solitária, experiente, urbana, que combina vivacidade, sabedoria, discernimento e carência de afeição. Sim, Simone logo se urbaniza e se situa na grande cidade, revelando-se muito à vonta de, não só na academia e no pugilismo como também na agilidade e na labialidade com que lida com tudo o que é urbano; podendo ser episódico, descompromissado, irresponsável, nocivo, solitário, desesperado.

$\mathrm{N}$ ão vim me congratular contigo por teus sucessos. $\mathrm{N}$ ão me interessa ninguém. Q uero somente dinheiro.Tudo que tiver. Logo...Tenho de ir-me embora. Logo... É sangue. Ela se agarrou em minhas costas. N ão queria me largar. N ão queria morrer... N inguém me viu e não há razões para que suspeitem de mim (I dem, pp. 282-283).

R occo é a encarnação dos ideais da mãe e do pai ausente, buscando sempre manter todos em comunhão, junto com a mãe, no espírito da migração; tentando fazer com que a família realize a missão pela qual se pôs na estrada. É assim que se ajusta ao mundo urbano, movendo-se nas diferentes atividades, inclusive no pugilismo, a despeito de não gostar. Para garantir o clima da comunidade, engaja-se na sociedade, no labirinto turbulento. $\mathrm{E}$ de repente se apaixona por $\mathrm{N}$ adia, que descobre nele 0 amor e a amizade, a transparência e a felicidade. R occo tem algo de santo. $M$ antém uma atividade compreensiva e empenha-se nela, concentrada na família, a comunidade originária enraizada no cristianismo primordial. Tanto é assim que se deixa brutalizar por Simone, para salvá lo, inclusive fazendo com que $\mathrm{N}$ adia volte para ele, para salvá-lo; inclusive chorando desesperado com ele após o assassinato de $\mathrm{N}$ adia, para salvá lo.

Ciro. 0 uve. Eu não creio na justiça dos homens, não é para nós... D evemos só defendê-lo...Ajudá-lo... Paraque servirá? Q uem nos escuta?Todosinimigos. Eiso que nos tornamos. uma família inimiga. M as, por que blasfemar? $\mathrm{N}$ ós erramos e nós devemos pagar. D evemospagar (Idem, pp. 285-286). 
Ciro logo se torna operário. M ove- se com confiança e desempenho na profissão, empregado na indústria automobilística. Está situado, comprometido com a família e preocupado com os desvios de Simone, enquanto R occo empenha-se em proteger e salvar Simone, inclusive das transgressões contra si próprio. M ais integrado na cidade, Ciro vê os problemas da família e o contraponto entre Simone e R occo com olhar realista, certo distanciamento crítico, uma visão política. Expõe o dilema "Simone" em termos nítidos, relembrando algo da sabedoria antiga, lá da terra.

Irmão ou não, eu não quero mais saber dele... N ós somos como sementes do mesmo saco... Sementes que devem por sua vez dar frutos sãos. Se em nosso meio há um que se torna mau, podre, transviado, é preciso separar dos outros como quando mamãe nos dava lentilhas para catar... (Idem, p. 252).

Ciro parece ter uma visão mais política dos problemas da família. Sua experiência de operário, simultaneamente urbano, movendo-se na sociedade atravessada por diversidades e desigualdades, permite-Ihe ver com clareza, ou frieza, aspectos importantes dos impasses da família, da tragédia em formação. E comenta com Luca o desfecho dos acontecimentos.

Q uando você ficar grande, vai compreender que foi injusto comigo... Foram todos injustos... N enhum de vocês quis tanto bem a Simone quanto eu. Q uando chegamos do sul, eu tinha tua idade. Foi Simone quem me explicou aquilo que Vincenzo não entendeu. Simone me dizia que nós lá no sul tínhamos vivido como animais, dependendo do humor e da generosidade de um patrão. M e explicou que era preciso aprender a fazer valer nossos direitos depois de ter aprendido a conhecer nossos deveres. D epois, Simone se esqueceu dessas coisas. Eu procurei aprender a conhecer meus direitos e meus deveres... Eu não 0 denunciei, mas é como se tivesse feito. Simone é um doente que suja tudo. Espalhou o ódio e a discórdia em nossa casa... E também te estragava, quando podes vir a ser o melhor de todos nós porque aprenderás com nossa experiência. A malvadez dele é tão nociva quanto a bondade de Rocco. Isso te parece estra nho? É assim, Rocco é um santo. M as no mundo em que vivemos, na sociedade que os homens criaram, não há mais lugar para santos como ele. A piedade dele provoca desastres (Idem, pp. 288-289). 
conflitos, as aflições, os contentamentos e os sofrimentos, principalmente como espectador. Alegra-se e sofre com um, com outro e com todos. Também ele migrou de Lucania e pensa um dia regressar, imaginando que Rocco voltará. Em Luca ainda continuam a ressoar as diferentes vivências do campo, como memória idealizada, refúgio de tranqüilidade ou lugar da transparência, difíceis ou impossíveis na cidade. M as Ciro, generoso e lúcido, Ihe diz que talvez Lucania já não seja a mesma.

Se R occo voltar para nossa terra, diz Luca, volto com ele. N ão penso que R occo consiga voltar nunca pra lá, responde C iro. E o que pensa que pode encontrar de diferente naquela zona? Também nosso lugarejo há de transformar em grande cidade, onde os homens aprenderão a fazer valer seus direitos e cumprir com seus deveres. Eu não sei se um mundo assim é belo... (Idem, p. 289).

$\mathrm{N}$ adia é a expressão viva, ágil, à vontade, do mundo urbano, dasfímbrias entre 0 dia e a noite, o permitido, o tolerado e a transgressão, 0 desfrute e a paixão. Busca o diálogo, a compreensão, o amor. É vivida, experientee carente, nos termosda cultura da cidade, o teatro no qual perambulam desconhecidos e conhecidos, amigos e irreconhecíveis. Combina algo de ceticismo com resignação, em busca de nesgas de romantismo. D epois de estar afastada de Simone, com quem havia rompido temposatrás, aproxima-se de R occo. Sente-se fascinada por sua personalidade e generosidade, a imensa capacidade de compreensão. A paixona-se. $D$ aí nascem o ciúme, o ressentimento e a vingança de Simone, que a assassina. É como se o camponês enraizado em suas tradições seculares de repente emergisse daquele pugilista lumpenizado; quem tão rapidamente se havia urbanizado também rapida mente se entrega à vendetta originária, primordial.

Q ue é?Te impressiona tanto assim que uma pessoa qualquer tenha andado presa? O Iha que não é tão estranho assim... A final, não sou a única no mundo - acrescenta, conversando com R occo. 0 que é que devia te dizer? Sabe muito bem de tudo. 0 que tive com Simone foi o mesmo que com todos os outros. $\mathrm{N}$ ão te escondi nada. Sabia de tudo. N ão menti. Eu te disse tudo (Idem, pp. 200 e 231).

E acrescenta, no diálogo final com Simone:

$\mathrm{N}$ ão tenho medo... É dinheiro que quer? Ir embora? Pra onde? Contigo? Está maluco. $\mathrm{O}$ lha, Simone, me deixa em paz... N ão pode saber como te odeio...Tu és 
uma pessoa vil, um animal, não é um homem...Tudo o que cai em tuas mãosfica vulgar, porco, estragado... Agora, pode fazer tudo o que quiser, nada mais me importa (Idem, pp. 272-275).

Tudo na gesta da família Parondi é vivência. Sucedem-se situações, atividades, realizações, frustrações, ilusões. São experiências individuais e coletivas, reais e imaginárias, presentes e pretéritas. Esse é o emaranhado no qual se revelam as mais diversas formas de consciência. A despeito da impressão de que todos vivem a mesma situação, são distintas as modulações da consciência em cada um. Esse é o enigma da metáfora "somos como os cinco dedos da mão". Poderiam estar não só juntos, mas unidos, em conformidade, convívio, harmonia. M esmo porque a mãe é a maestra que busca sempre acomodar cada um e todos, como as vozes de um coro, as vibrações da melodia. M as a polifonia logo explode em cacofonia. $C$ ada um fala, pensa, sente e age diferente. A inda que R occo se revele figuração da mãe e da memória do pai, a cacofonia não só continua como se torna estridente, desesperante. D aí a nostal gia ressoando de quando em quando, como um eco de um mundo pretérito. "O xalá nunca tivéssemos vindo de nossa terra... M as o fato é que esse era nosso destino. 0 teu, o meu, o de Simone", diz Rocco a Ciro. E este responde: "M as pensa que vida seria a nossa se ficássemos lá". E R occo retorna: "Estávamos ainda todos unidos" (Idem, pp. 252-253).

Depois da longa jornada, do longínquo sul ao desconhecido norte, do campo à cidade, a família Parondi chega tensa e cansada, mas contente e transparente. Todos se comunicam rápida e facilmente. 0 estado de espírito é fluente, a despeito das incertezas sobre como, onde e quando se situar na grande cidade. Logo se engajam no vaivém urbano, na busca do emprego, de alguma base para organizar a vida. Salvo o menor, que ajuda a mãe na casa e contracena com os irmãos, todos movem- se, buscam, situam-se. E desenvolvem contatos com diferentes pessoas e organizações. M ultiplicam suas relações. R edefinem-se, assumindo-se no estranho mundo da cidade, todos em atividades subalternas. Aos poucos, no entanto, surgem divergências, desentendimentos, desencontros, atritos. A fastam- se e dispersam-se, a despeito de continuarem a pertencer ao mesmo núcleo, se referirem ao mesmo lugar, circularem à volta da mãe. D e repente, revelam-se alheios, distantes, estranhos. A transparência se apaga na opacida de. É como se de um momento para o outro viesse à tona algo que estivera encoberto, escondido, à espreita. 0 que parecia uma balada torna-se 
uma dança macabra.

0 principal palco dessa história é a família, reverberando o que havia no campo e 0 que há na cidade. $\mathrm{N} 0$ seio dela medram 0 sentimento e 0 sofrimento, a alegria e a dor, a esperança e a decepção. 0 que pode ser comunhão pode ser também alucinação.Tudo o que ocorre lá longe, no campo, terra ou sul, na realidade ou na memória, tudo ressoa na família. Ela nasce, desenvolve-se, transforma-se e perdura como ilusão de comunidade, sendo simultaneamente ambiente de ressonâncias de grande parte do que acontece na cidade. É sempre atravessada e desafiada pelas tensões que medram na sociedade, mas subsiste pertinaz como a comunhão da comunidade. Subsiste como compromisso e aspiração, em meio ao constante torvelinho que se desenvolve naquele ambiente. A os poucos ela sofre tensões e se modifica, esgarça e se desfaz. $M$ as todos reiteram a presença, reafirmando a comunhão que alimenta a transparência da comunidade; podendo também germinar as surpresas da dispersão.

São todos, os irmãos, a mãe e $\mathrm{N}$ adia, figuras e figurações da mesma gesta, uma trajetória errática, uma travessia sem fim, um fluxo contínuo de inquietações, discernimentos, sofrimentos, aflições. Estão sendo levados pelo destino, preparados e preparando-se para o desfecho que se forma nos interstícios do cotidiano da casa e da cidade.

A tragédia cumpre-se inexorável. $\mathrm{N}$ inguém pode fazer nada contra ela. A bate-se sobre todos, $\mathrm{N}$ adia, Simone, R occo, avassaladora. $\mathrm{N}$ inguém está imune. Todos são convocados pelo destino. R esta somente entregar-se, sem nenhuma resistência, inerme. $E$ chorar. 0 pranto convulsivo e desesperado de Simone e de R occo é o fundo do abismo, e o cume da montanha. Aí se instaura o silêncio, um vasto silêncio cobrindo a casa e a cidade.

U ma tragédia em cinco atos, assim nomeados: "V incenzo", "Simone", "R occo", "C iro", "Luca"; atravessada pelas vozes de "R osaria" e"N adia", fazendo coro, vaticinando inexoráveis irrupções do destino. U ma tragédia que vai fundo no espaço e no tempo. Mergulha no sul e no norte, na comunidade e na sociedade, na memória e no esquecimento, na história e no mito. Lá longe, no fundo do esquecimento e do mito, está Lucania, de onde vieram os Parondi. É o sul, o meridióne, a terra remota, pretérita. Aí, em outros tempos, estiveram os romanos, os gregos, os árabes, os espa nhóis, como povoadores e aventureiros, conquistadores e piratas, escravos e senhores, homens e deuses. É como se os Parondi estivessem expiando façanhas antigas, rebeldias míticas. U m destino desconhecido, um enigma perdido no fundo dos tempos. 
Todo migrante é também viandante, peregrino, fugitivo, aventureiro, viajante ou retirante. Está em busca de outros ares, terras, perspectivas de vida, modos de ser. Foge do que conhece e busca o que desconhece. I magina o futuro como negação do passado, surpreendendo-se com 0 presente. Aventura-se, arrisca-se. Imagina chegar em outro lugar, encontrar outras possibilidades de vida e trabalho, realização e emancipação. Entretanto, desde o momento em que parte lança-se em uma travessia que não termina nunca, quer seja derrotado, quer seja vencedor.

U ns viajam sós, outros com a família. Também há os que partem com amigos, inclusive desconhecidos. M as também as gerações migram. $C$ ada um leva consigo, em sua vivência e imaginação, pais e filhos, irmãos e irmãs, avós e netos, parentes e ausentes, presentes e remotos. Além das gerações sucessivas que migram, no mesmo tempo ou em outros tempos, há a migração imaginária dos que ficam. Escrevem-se cartas, enviam-se mensagens, buscam- se notícias, guardam- se fotografias. Sim, os que ficam na terra, minifúndio, latifúndio, feudo, bai rro, povoado, vilarejo, ermo ou páramo, essestambém não param nunca de viajar. Permanecem na expectativa, indiferentes ou tensos, alegres ou tristes, inquietos ou desorientados, esperançosos ou resignados, seja pelo que ocorre com os que se foram, seja pelo que imaginam sobre eles; seja, ainda, pelas dúvidas e certezas que alimentam sobre si mesmos, lembrados e esquecidos. Sim, tanto os que partem como os que ficam, todos levam consigo a sensação de uma insondável travessia.

0 migrante pode ser visto como aquele que foge e busca, é tangido e extravia-se, ambiciona e frustra-se, resigna-se e realiza-se. São muitos os que se perdem na viagem, ficam pelo caminho, regressam e retornam. Parecem tangidos por uma força desconhecida, simultaneamente histórica e telúrica.

0 migrante pode ser um e muitos, famílias e grupos, coletividades e povos. São viandantes de uma vasta e errática diáspora que se espalha pelas naçõese continentes, com suas vozese línguas, cores e coloridos, atividades e padecimentos, frustrações e al egrias. Podem real izar-se na primeira ou na última geração; ou malograr em todas. Estão metidosem situaçõese acontecimentos, guerrase convulsões so ciais, lutas políticas e revoluções, carênciase esperanças. Podem ser vistoscomo uma multidão em movimento, ao acaso de situaçõese acontecimentos, como que tocadospelos ventos.

0 século $X X$ tem sido um século de migrações, pelos quatro cantos do mundo, em todas as direções. São desempregados, desabrigados, refu- 
giados, perseguidos, desamparados. São indivíduos e familiares, grupos e coletividades. São muitos, milhares, milhões. M ovem- se em todas as direções, atravessando territórios e fronteiras, nações e continentes, culturas e tradições. São migrantes, emigrantes, imigrantes, retirantes, errantes. Parecem tangidos por algo imponderável e invisível, escondido nas condições de vida e de trabalho, no meio de guerras e revoluções, nos desastres ecológicos e nas epidemias, mesclando carências e esperanças.

U m dos aspectos mais notáveis das migrações em curso no século XX expressa o modo pelo qual se desenvolve a nova divisão transnacional do trabalho e da produção. Em sua grande maioria, os migrantes são ou transformam-se em trabalhadores em busca de emprego. Exercem as mais diversas atividades, em geral as menos qualificadas social e economicamente, conforme este ou aquele contexto social; situam-se como los de abajo, os "humilhados e ofendidos", membros das "classes perigosas", ameaça aos que já estão empregados e mais ainda aos já desempregados.

Esse é realmente um aspecto importante de boa parte dos movimentos migratórios em curso no século XX : são trabalhadores desempregados ou empregadosem condições extremamente adversas, buscando outrase meIhorescolocações. Partem sozinhos, com seusfamiliaresou em grupos. Seguem estradas e viagens inauguradas por outros, ou abrem novas estradas. D eslocam-se para as mais diversas direções, a procura de lugares próximos, distantes, longínquos. Sempre em busca de emprego, isto é, sempre empenhados em vender sua força de trabalho, para comer, beber, vestir-se, abrigar-se, proteger a saúde, estudar, conquistar direitos políticos, civise sociais; como indivíduos e famílias, coletividades e povos.

A decisão de partir, na esperança de poder realizar um projeto próprio de existência, seja nos confins da própria nação ou região, seja além do oceano, implica evidentemente processos de mobilidade geográfica, cultural, econômica, social e profissional que, no encontro e no desencontro de populações, assumem uma importância fundamental; so bretudo em sociedades caracterizadas por complexas e irresistíveis dinâmicas de intercâmbio, internacionalização e globalização, tais como se podem considerar as sociedades contemporâneas (Lazzari, 2000, p. 17).

$\mathrm{N}$ ote- se que grande parte da vida do migrante se desenvolve na cidade, muitas vezes em grandes centros urbanos. M uitos saem do campo e de pequenas localidades, desde longínquos países, e dirigem- se para as cidades que parecem prósperas, promissoras. Aí encontram dificuldades e pers- 
pectivas, emprego e desemprego, pauperismo e lumpenização, êxito e emancipação. A lguns conseguem ascender socialmente, realizam-se, chegam a sentir-se vitoriosos. 0 utros, muitos, a grande maioria, dissolve-se no meio da multidão solitária.

A cidade torna se o lugar privilegiado da contradição e do embrutecimento, na pobreza e na miséria sem esperança; da estabilidade precária e da persistente imobilidade social, quando não de um ulterior descenso ao inferno da miséria (I dem, p. 33).

Simultaneamente, nesse emaranhado de situações e acontecimentos, de par em par com as migrações e as errâncias, desenvolve-se um novo ciclo de radialização do mundo, envolvendo as formas de sociabilidade, as condições de vida e de trabalho, os jogos das forças sociais; tudo isso concretizado na fábrica e no escritório, sindicato e partido, escola e igreja. Essa é uma implicação sempre presente e ativa nos processos migratórios: criam-se e explicitam-se tensões étnicas, lingüísticas e religiosas. A xenofobia, o etnicismo, o racismo e o fundamentalismo emergem ou ressurgem em situações sociais nas quais o migrante aparece como "diferente", "estrangeiro", "exótico", "outro". Simultaneamente à acomodação, à integração e à participação em curso nos locais de trabalho e de convívio social, emergem e ressurgem tensões e conflitos. U ma parte do "neonazi smo" de que se fala em diversas nações pode ser visto como "produto" da racialização em curso no fim do século $X X$ e início do $X X I$. Permeando a luta pelo emprego, 0 crescimento do desemprego conjuntural e estrutural, a busca de residência, escola, saúde e outras condições básicas de vida, emergem e ressurgem idiossincrasias raciais de todos os tipos; são xenofobias, etnicismos, racismos e fundamentalismos que se exacerbam, nascem ou renascem em várias das sociedades do "primeiro, ex-segundo e terceiro mundos". Em pouco tempo as nações que haviam lutado contra o nazifascismo descobrem e redescobrem que também contêm intolerâncias e fundamentalismos desse mesmo cunho.

C abe reconhecer, no entanto, que a multidão de migrantes que se espalha pelo mundo envolve um vasto processo de transalturação. São muitas as culturas que se encontram, acomodam, sofrem tensões, negam e recriam. R ecriam-se geralmente em outros e novos termos. São intercâmbios de valores e instituições, formas de sociabilidade e ideais, línguas e religiões; além de mestiçagens ou hibridações. Assim se multiplicam as 
formas e as práticas culturais, as histórias e as tradições, as alteridades e as diversidades. Assim se multiplicam as pluralidades socioculturais, compreendendo as práticas e as criações de indivíduos e coletividades. Encontram- se, cruzam-se, reafirmam- se e tranformam-se as muitas" identidades", de tal maneira que o ocidentalismo e o orientalismo, assim como 0 indigenismo e o africanismo, mudam de figura, redefinindo-se em outros termos, em diferentes significações.

$\mathrm{N}$ a complexa teia das suas relações sociais, os transmigrantes organizam e criam múltiplas e fluidas identidades, buscadas simultaneamente em sua sociedade de origem e nas adotivas. Enquanto alguns migrantes identificam-se mais com uma sociedade do que com outra, a maioria parece desenvolver várias identidades, relacionando-se simultaneamente com mais de uma nação. Ao manter muitas e diferentes identidades raciais, nacionais e étnicas, os transmigrantes tornam-se aptos a expressar as suas resistências às situações econômicas e políticas globais que os envolvem, bem como para se ajustarem às condições de vida marcadas pela vulnerabilidade e a insegurança. Estes migrantes expressam essa resistência em pequenos gestos, em práticas cotidianas, que habitualmente não desafiam ou nem mesmo reconhecem as premissas básicas dos sistemas que os envolvem e ditam as condições da sua existência. Como os transmigrantes vivem simultaneamente em diversas sociedades, suas ações e crenças contribuem para a contínua e múltipla diferenciação. A crioulização [...] não é somente o produto de uma acentuada distribuição mundial de sistemas [de referência], mas também o produto dessa dinâmica envolvida na migração e na diferenciação [...]. N a economia globalizada desenvolvida ao longo dasúltimas décadas, háuma convicção de que nenhum lugar é verdadeiramente seguro, embora o indivíduo tenha acesso a muitos lugares. U ma forma de os migrantes manterem suas opções abertas é transladarem-se continuamente, de uma posição econômica e social conquistada em um ambiente político para outra posição política, social e econômica em outro ambiente (Schiller et al., 1992, pp. 11-12).

$\mathrm{N}$ o contexto das migrações transnacionais, tanto se desenvolvem as intolerâncias como as acomodações, o neo-nazismo ou o nazifascismo como a transculturação, as identidades e as alteridades, os fundamentalismos e os cosmopolitismos. Esse também o contexto em que se desenvolve 0 debate sobre o multiculturalismo. Em pouco tempo, nas últimas décadas do século $X X$, são muitos os que se engajam em controvérsias, práticas e elaborações teóricas sobre o multiculturalismo. É como se o étnico, 0 
racial e o gênero, sem esquecer gerações, logo se revelassem categorias fundamentais da organização e da dinâmica da sociedade, em âmbito nacional e mundial. São categorias com as quais se passa a descrever e a explicar grande parte da realidade social. 0 debate so bre multiculturalismo, envolvendo etnicismo e sexismo, logo se torna não só relevante, mas predominante. Em larga medida, o que está em causa é a liberação, a conquista de identidades individuais e coletivas, a afirmação de alteridades e diversidades. $\mathrm{N}$ o limite, está em causa 0 indivíduo, a individuação, 0 individualismo, tomados como condição e afirmação de cidadania. Pouco ou nada se diz da história e da dinâmica da sociedade, do jogo das forças sociais, das hierarquias e contradições de classes, da "fábrica" de intolerâncias e autoritarismos.

Todo migrante define-se pela viagem, como refugiado, retirante, indocumentado, legal, clandestino, esperado, expulso, radicado, errante. Ainda que esteja localizado, enraizado ou integrado, ainda guarda em si algo do viajante, de quem está em trânsito, literal ou metaforicamente. M esmo aquele que nunca saiu do seu lugar, que está enraizado por gerações, mesmo esse, no contraponto com o migrante recente ou antigo, sente-se desafiado pela viagem do outro. Esse é um estado de espírito que perpassa a percepção e a atividade, o modo de ser e a subjetividade de uns e de outros. Aquele que vai e aquele que fica, o que chegou e o que estava, todos sentem-se em viagem, real ou imaginária, literal ou metafórica, presente ou pretérita; vagando no futuro (cf. Ianni, 1972).

É nesse clima que o migrante desenvolve várias e muitas possibilida des de agir, pensar e sentir, ser e devir. Desenvolve perspectivas plurais, múltiplas, polifônicas. Pensa-se em movimento, sente-se em diferentes situações, padece distintas injunções, defronta-se com diversas e prementes carências. Simultaneamente, percebe o singular e o plural, a vivência e a perspectiva, 0 ser e 0 devir.

$N$ esse sentido é que o migrante tende a desenvolver uma percepção de "si" e do "outro", do "nós" e dos "outros", que pode ser uma percepção diversificada, plural, múltipla. A condição de migrante é, simultaneamente, a de quem está aqui elá, em duasou maissituações, perspectivas, modosde ser. Pode desenvolver certa eqüidistância, visualizar criticamente a socieda de adotiva e a originária, colocar-se em condição de "marginal" .É desafia do a pensar-se e a sentir-se no contraponto do "eu" e do "outro", "nós" e "eles", nativo e estrangeiro, como em um jogo complexo de espelhosreflexOS. D aí a possi bilidade de uma autoconsciência sui generis, na qual se com- 
binam 0 singular e o plural, a identidade e a alteridade, a integração e 0 antagonismo, a acomodação e a transformação (cf. Stonequist, 1948).

São diversos os grupos étnicos que se definem pela condição essencial de migrante. Povoam muitoslugares no mapa do mundo. C omo o "árabe" em países da Europa, da África, da Ásia e das A méricas; ou o "oriental", seja ele japonês, coreano, chinês, hindu ou outro, em países da Europa, da África e dasA méricas; ou o "negro", originário da vasta e longa diáspora provocada pela escravatura moderna, vivendo por gerações sucessivas em países das A méricas. A despeito da abolição do regime de trabalho escravo, da sucessão de gerações, das mestiçagens de todos os tipos, de al gumas conquistas sociais, os negros das A méricas continuam a definir-se como indivíduos e coletividades em viagem, tangidos desde longe, em busca de raízes. Daí a autoconsciência plural, capaz de apreender a perspectiva múltipla, emaranhada.

Esta é a lição dessa história: na sociedade mundial, assim como na sociedade nacional, o migrante continua a ser tangido por situaçõese acontecimentos, como que fustigado pelos ventos. Pode ser apenas um, solitário, retirante, perseguido, ambicioso, viandante; mas podem ser muitos, milhares, milhões, afetados por desastres ecológicos e epidemias, guerras e revoluções, xenofobias e etnicismos, racismos e fundamentalismos, em busca de trabal ho, refúgio, raízes, paz. C ontinuam a percorrer territóriose fronteiras, continentes, ilhas e arquipélagos, levando pelos caminhos as marcas dos próprios passos, desenhando no mapa do mundo os sinais de suas errâncias.

\section{Referências Bibliográficas}

IAN N I, C onstantino. (1972), H omens sem paz . R io de Janeiro, C ivilização Brasileira.

LAZZAR I, Francesco. (2000), L 'attore sodale fra appartenenze e mobilità: analisi comparatee proposte socio-educative. Pádua (I tália), C edam.

Schiller , N inaG lick; Basch, Linda\& Blan C-Szanton , C ristina (orgs.). (1992), "Towards a transnational perspective on migration". A nnals of the N ew York A cademy of Sciences, 645: 1-24, N ovaYork, The N ew York Academy of Sciences.

ST O N EQ UIST , Everett V. (1948), 0 homem marginal: estudo de personalidade e conflito cultural.Tradução de A sdrubal M entes G onçalves. São Paulo, Livraria M artins.

Vısc o N TI, Luchino. (1967), R occo e seus irmãos. Tradução de N oênio Spinola. R io de Janeiro, C ivilização B rasileira. 


\section{Resumo}

0 texto empreende uma leitura sociohistórica da dramática experiência de uma família de migrantes (a família Parondi) do sul rural da I tália para a metrópole industrial de M ilão, por meio das vivências conflituosas expressas pelos protagonistas - a mãe, os cinco filhos, suas mulheres-, tal como recriadas no clássico filme neo-realista do diretor italiano Luchino V isconti, R occo e seus irmãos (R occo i suoi fratelli), de 1960. Palavras-chave: Arte e sociedade; M igração; C lasses trabalhadoras; $\mathrm{C}$ ampo e cidade; Experiência social e afetividade.

\section{Abstract}

The text undertakes a moving historical appraisal of the dramatic experiences faced by afamily of migrants (the Parondi family) through their move from the rural south of I taly to the industrial metropolis of $\mathrm{M}$ ilan, pointing out the expressive conflicting lives of the characters - the mother, the five male siblings, their women -, just as performed in the classic feature film by neo-realist Italian director Luchino Visconti, R occo and his brothers ("R occo i suoi fratelli"), of 1960.

Keywords: Art and society; M igration;W orking classes; C ountry and city; Social experience and affectivity.

O ctavio Ianni foi professor-emérito da Fa culdade de Filosofia, Letrase Ciências H umanas da U niversidade de São Paulo. 